\title{
Influence of strain rate on buckle folding of an elasto-viscous single layer
}

\author{
F.S. Jeng ${ }^{\mathrm{a}}{ }^{*}$, M.L. Lin ${ }^{\mathrm{a}}$, Y.C. Lai ${ }^{\mathrm{b}}$, M.H. Teng ${ }^{\mathrm{b}}$ \\ ${ }^{\mathrm{a}}$ Department of Civil Engineering, National Taiwan University, Taipei 10617, Taiwan \\ ${ }^{\mathrm{b}}$ Department of Geosciences, National Taiwan University, Taipei 10617, Taiwan
}

Received 22 September 2000; revised 1 June 2001; accepted 15 June 2001

\begin{abstract}
The influence of strain rate on the buckle folding behavior of an elasto-viscous layer-matrix model is explored by adopting an endrotation method, which is capable of excluding the influence of initial geometric perturbation, and by observing the energy variation in the system. The results indicate that, if the strain rate is relatively slow, the folding behavior is in fact the result of both viscous and elastic behavior, and not just the viscosity alone.

For two-stage shortening at different strain rates, the final waveform depends on either the earlier strain rate inducing buckling or the later strain rate applied in the post-buckle stage of deformation. If the later strain rate is relatively fast, the final waveform will be similar to the one yielded by the fast strain rate alone, as a substantial amount of elastic energy can be accumulated during the subsequent fast deformation. On the other hand, if the later strain rate is relatively slow, the earlier waveform is retained and further amplified during the slower post-buckle deformation. This results from the phenomenon that an initial geometric perturbation is amplified into a fold, if the applied strain rate is very slow. (C) 2002 Elsevier Science Ltd. All rights reserved.
\end{abstract}

Keywords: Numerical simulation; Fold; Elasto-viscous behavior

\section{Introduction}

Folding of rock strata is a fascinating phenomenon that has attracted geologists to explore the underlying mechanisms that cause fold waveforms. Field observations have focused on the wavelength and thickness of the competent layer (Sherwin and Chapple, 1968). The understanding and interpretation of folds have been discussed in many publications (e.g. Biot, 1959, 1961; Ramberg, 1963, 1964; Johnson, 1970, 1977; Price and Cosgrove, 1990; Johnson and Fletcher, 1994). It has been found that the wavelength of folds developed during layer shortening is related to the competence contrast between the embedded rock layer with the surrounding matrix. The materials concerned showed either viscous (Biot, 1961; Ramberg, 1963) or elastic behavior (Karman and Biot, 1940; Biot, 1961; Currie et al., 1962), or a combination of both, i.e. elasto-viscous behavior (Hunt et al., 1996; Whiting and Hunt, 1997; Schmalholz and Podladchikov, 1999, 2000). Table 1 summarizes the material model adopted for the competent layer and the matrix in relevant publications.

For a single viscous layer embedded in a weaker viscous matrix, a dominant wavelength of the fold exists and can be

\footnotetext{
* Corresponding author. Tel./fax: +886-2-3630530.

E-mail address: fsjeng@ce.ntu.edu.tw (F.S. Jeng).
}

expressed in terms of the viscous competence contrast as (Biot, 1961):

$\left(l_{\mathrm{cr}}\right)_{\mathrm{v}}=2 \pi h \sqrt[3]{\frac{\eta}{6 \eta_{0}}}$

where $\left(l_{\mathrm{cr}}\right)_{\mathrm{v}}$ is the dominant wavelength, $h$ is the thickness of the layer, $\eta$ is the viscosity of the layer and $\eta_{0}$ the viscosity of the matrix.

On the other hand, for perfectly elastic materials, a dominant wavelength also exists but in this case, it is expressed in terms of the elastic competence contrast as (Currie et al., 1962):

$\left(l_{\mathrm{cr}}\right)_{\mathrm{e}}=2 \pi h^{\frac{3}{6}}$

where $\left(l_{\text {cr }}\right)_{\mathrm{e}}$ is the dominant wavelength, $E$ is the Young's modulus of the layer and $E_{0}$ the Young's modulus of the matrix.

It is commonly recognized that the deformational behavior of rock depends on the ambient temperature, the confining stress and the strain rate and that it shows shortterm elasticity and longer-term viscous creep effects (Mancktelow, 1999). If the rock is subject to a high temperature and high confining stress environment, which makes the rock analogous to a 'sticky fluid', it may deform viscously. 
Table 1

Summary of the material models adopted in relevant references

\begin{tabular}{|c|c|c|}
\hline \multicolumn{2}{|l|}{ Material model } & \multirow[t]{2}{*}{ Reference } \\
\hline Layer & Matrix & \\
\hline Elastic & Elastic & $\begin{array}{l}\text { Karman and Biot, 1940; } \\
\text { Currie et al., } 1962\end{array}$ \\
\hline Viscous & Viscous & $\begin{array}{l}\text { Biot, 1961; Ramberg, 1963; } \\
\text { Dieterich and Carter, 1969; } \\
\text { Hudleston and Stephansson, } \\
\text { 1973; Shimamoto and Hara, } \\
\text { 1976; Williams et al., } 1977\end{array}$ \\
\hline Elastic & Viscous & Biot, 1961 \\
\hline Elastic & Elasto-viscous & $\begin{array}{l}\text { Hunt et al., 1996; Whiting and } \\
\text { Hunt, } 1997\end{array}$ \\
\hline Elasto-viscous & Viscous & $\begin{array}{l}\text { Schmalholz and } \\
\text { Podladchikov, 1999, } 2000\end{array}$ \\
\hline Elasto-viscous & Elasto-viscous & $\begin{array}{l}\text { Zhang et al., 1996, 2000; } \\
\text { Mancktelow, 1999; this study }\end{array}$ \\
\hline
\end{tabular}

In this case, Eq. (1) is applicable for describing the folding behavior, especially for long wavelengths where the thin plate theory is appropriate (Fletcher, 1974, 1977). Alternatively, if deformation takes place in a relatively low temperature and low confining stress environment, the behavior of the rock tends to be 'elastic' such that the elastic behavior of the rock can possibly dominate the initial stages of folding (Price and Cosgrove, 1990).

In between these two extreme conditions, both elastic and viscous behavior may contribute to the waveform developed and an elasto-viscous model material has to be considered. Intrinsically, strain rates may affect the response of the elasto-viscous material. It has been observed that the folding behavior of such a material is comparable with either pure elastic material (Eq. (2)) or to viscous material (Eq. (1)), depending on whether the strain rate is relatively fast or slow (Zhang et al., 1996, 2000).

A measure, the dominant wavelength ratio $\left(\lambda_{\mathrm{d}}\right)$, indicating the type of response for an elasto-viscous layer embedded in viscous matrix has been proposed (Schmalholz and Podladchikov, 1999), in addition to the conventional Deborah number $\left(D_{\mathrm{e}}\right)$ :

$\lambda_{\mathrm{d}}=6^{-\frac{1}{3}}\left(\frac{\eta}{\eta_{0}}\right)^{\frac{1}{3}}\left(\frac{4 \eta \dot{\varepsilon}}{G}\right)^{\frac{1}{2}}$

$D_{\mathrm{e}}=\frac{\eta \dot{\varepsilon}}{G}$

where $G$ is the elastic shear modulus of the competent layer and $\dot{\varepsilon}$ the lateral strain rate. Furthermore, it has been found that the elasto-viscous model tends to have elastic or viscous folding behavior for $\lambda_{\mathrm{d}}<1$ and $\lambda_{\mathrm{d}}>1$, respectively (Schmalholz and Podladchikov, 2000).

A constant-amplitude sinusoidal waveform is considered for most of the above mentioned theories. However other waveforms, for example a sinusoidal wave with amplitude attenuation, exist in nature (Weiss, 1972) and have been reproduced in the laboratory (Price, 1975; Blay et al., 1977), as shown in Fig. 1.

This type of waveform, which results from an isolated initial perturbation, has been explored through experimental study and theoretical considerations (Cobbold, 1976; Abbassi and Mancktelow, 1990, 1992; Mancktelow and Abbassi, 1992; Mancktelow, 1999). It was found that the shape of the initial perturbation strongly influences the fold geometry, especially when the average wavelength component of the initial perturbation is larger than the dominant wavelength and the strain rate is slow (Abbassi and Mancktelow, 1992).

In addition to theoretical analyses of buckling of elastoviscous material, numerical simulation (e.g. finite element method; FEM) also serves as a versatile tool for exploring the mechanisms associated with buckle folding (e.g. Dieterich and Carter, 1969; Hudleston and Stephansson, 1973; Shimamoto and Hara, 1976; Cobbold, 1977; Mancktelow, 1999; Zhang et al., 1996, 2000). If a perfect thin layer is laterally compressed, the layer will shorten without folding. An initial perturbation is required to induce buckle folding of the layer when subjected to lateral compression. This initial perturbation may influence the final geometry of the waveform (Abbassi and Mancktelow, 1990, 1992; Mancktelow, 1999), especially when the strain rate is fairly slow (Zhang et al., 2000). Therefore, a perturbation method that will not influence the final waveform and only allow the effects of fundamental factors (including deformational modulus, viscosity, competence contrast etc.) to show up is required. This paper presents an alternative perturbation method, namely the end-rotation method, which does not involve introducing an initial geometric 'imperfection'. Based on this technique, the influence of the initial perturbation is excluded and the focus is then on the influence of material properties and strain rates on the waveform developed for an elastoviscous model.

\section{Modeling method}

\subsection{Proposed perturbation method}

If a perfectly straight layer without any perturbation is compressed, the layer is shortened without buckling. A perturbation is therefore required to induce folding in a numerical analysis and some initial geometric configuration different from a perfect-straight layer was generally adopted for this purpose (Zhang et al., 1996, 2000). However, this imposed initial geometric perturbation may dominate the waveform developed (Mancktelow and Abbassi, 1992; Mancktelow, 1999) and an alternative perturbation method is thus proposed in this paper.

The proposed perturbation, the end-rotational method, involves the imposition of a boundary rotation with an 


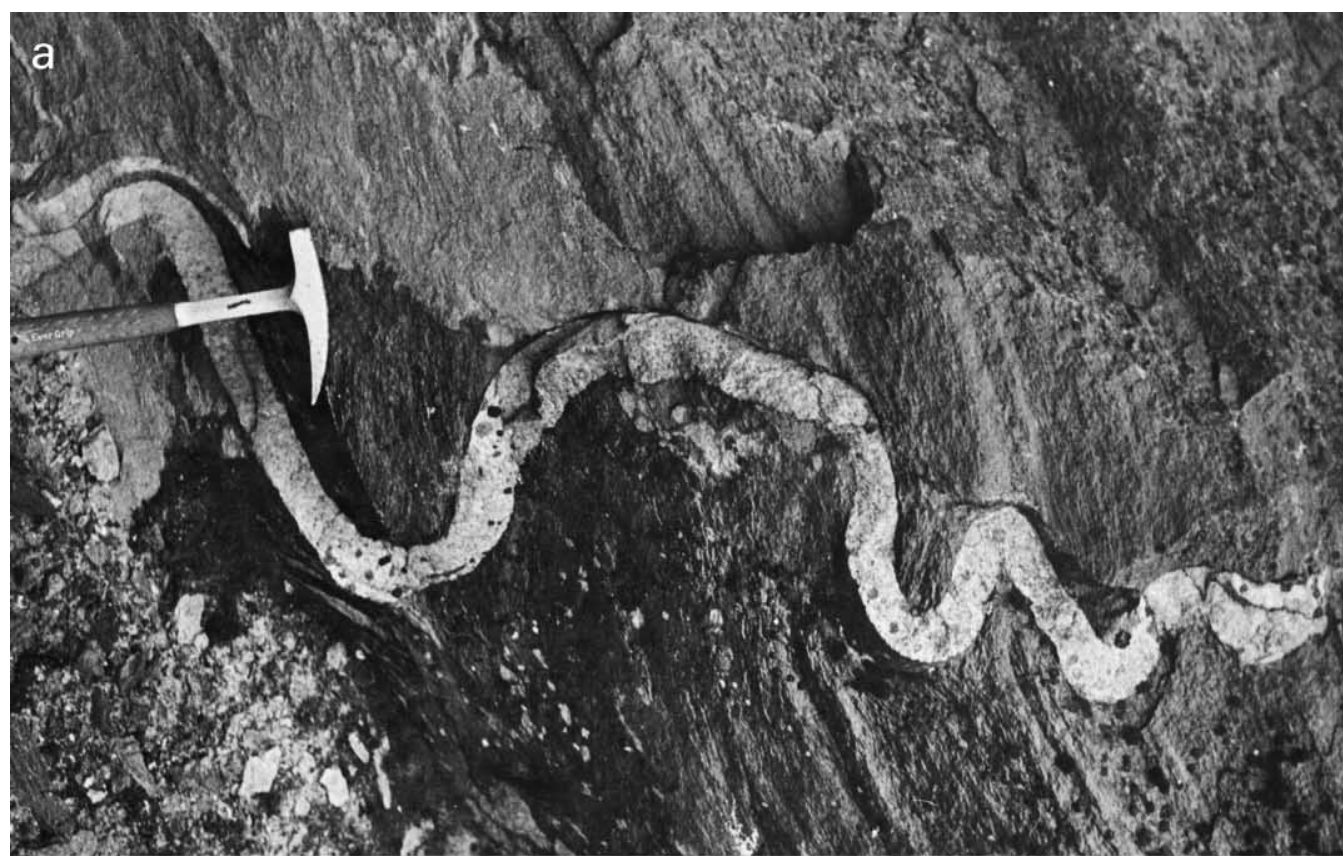

b
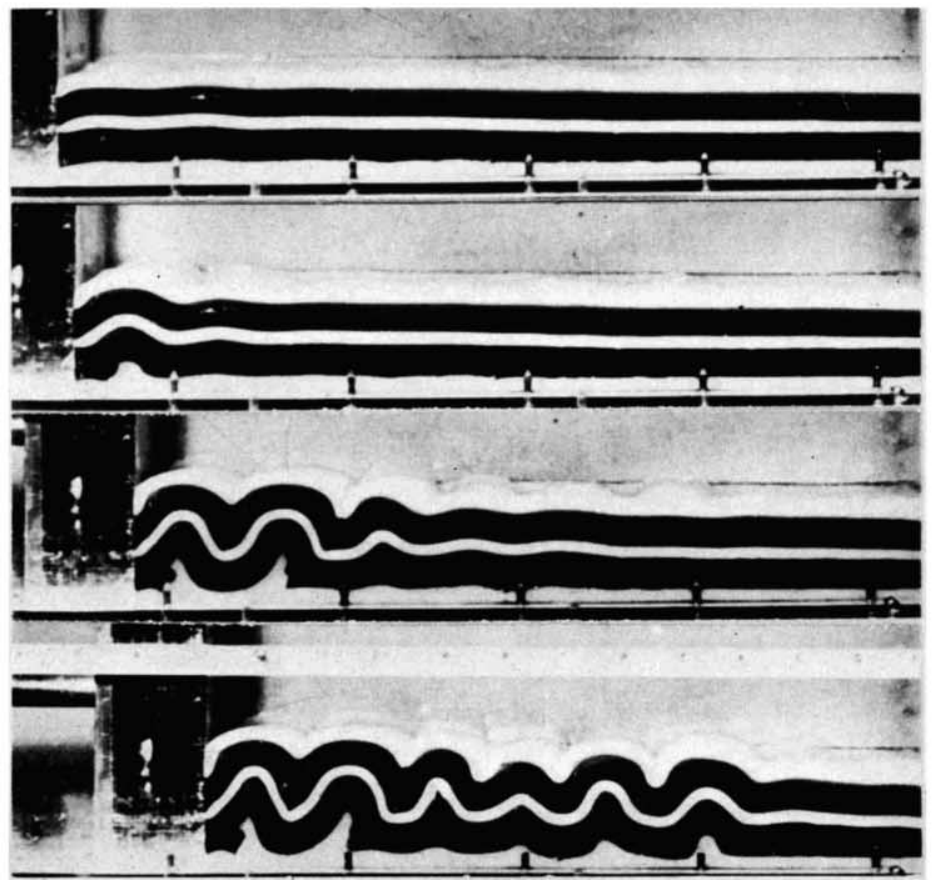

Fig. 1. Example of fold with attenuated amplitude. (a) Folded vein in foliated gneiss with amplitude attenuation toward the right end (after Weiss 1972, plate 171). (b) Analogue models of serial folding (after Price, 1975, plate 5).

angle $\theta$, small in magnitude, at either one or both ends of the layer, as illustrated in Fig. 2. By employing this endrotation, a moment is applied to the shortened layer, which accounts for the subsequent buckle folding. The rotation angle employed is selected to be very small, so as not to bend the layer too much. A typical range of rotation $(\theta)$ is $0.5 \times 10^{-1} \sim 0.5 \times 10^{-3 \circ}$, within which range the bending will not influence the waveform developed and identical waveforms can be obtained.

\subsection{Model configuration}

The geometry of the analyzed model and boundary constraints are identical to those adopted by Zhang et al. (1996, 2000) and Mancktelow (1999), allowing direct comparison. The competent layer has a length of $99 \mathrm{~h}$, where $h$ is the thickness of the layer, as depicted in Fig. 3. The matrix has a thickness of $33 h$ on both sides of the layer and a 'roller' constraint (free slip in the horizontal direction 


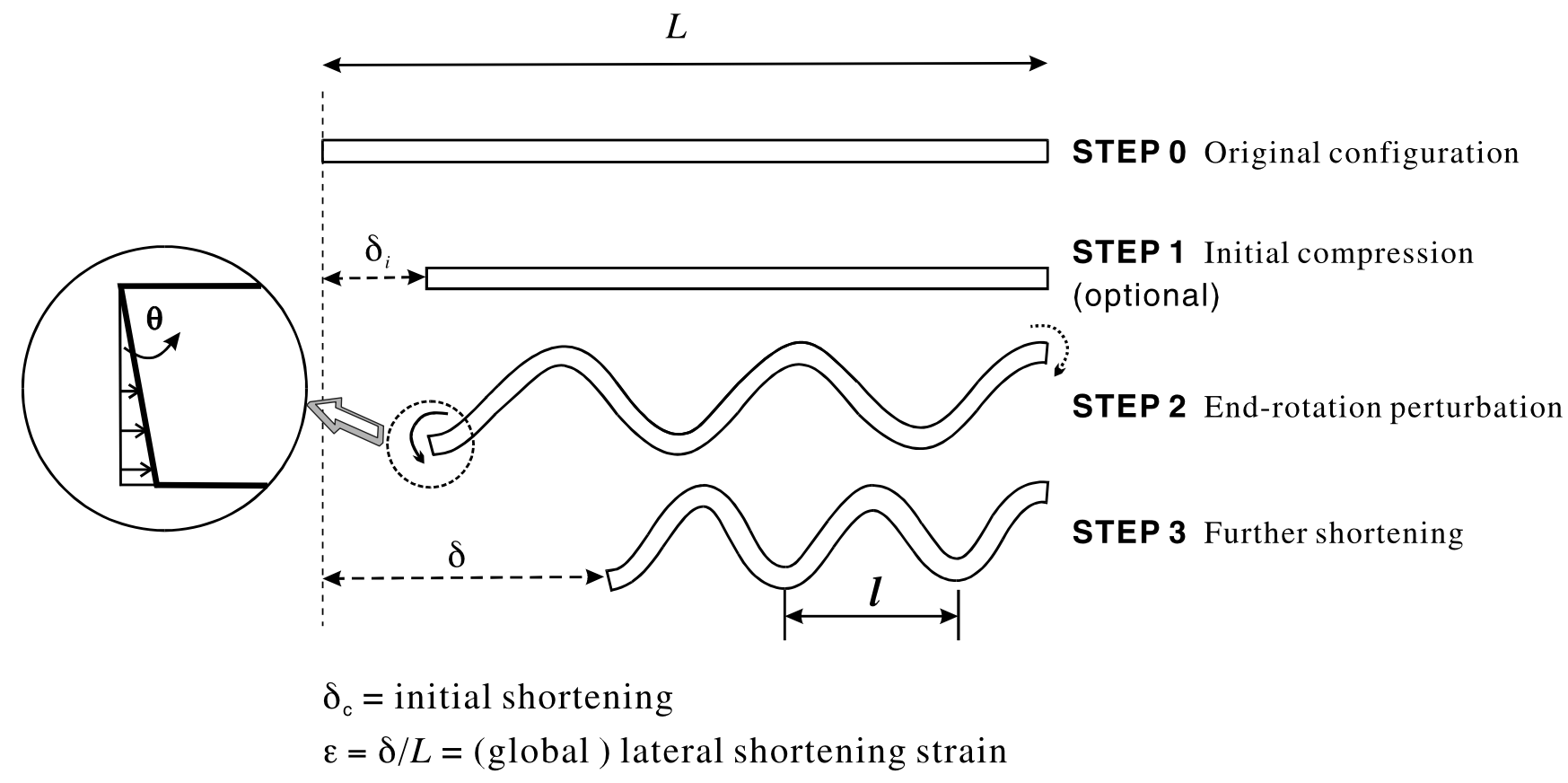

Fig. 2. Schematic illustration of the proposed end-rotation method adopted in numerical simulation. The perturbation is applied at the end of the competent layer by imposing a boundary displacement, with a rotation angle $\theta$, as shown in STEP 2 . An initial compression $\left(\delta_{\mathrm{i}}=5 \mathrm{~m}\right)$ was applied prior to end-rotation (STEP 1), which accounts for the lateral compression before perturbation takes place. After end-rotation is applied, further lateral compression is then applied (STEP 3) to obtain the buckle and post-buckle responses.

and no vertical displacement) is imposed along the peripheral boundary of the model. The material model adopted, the Maxwell elasto-viscous model, is also identical to Zhang et al. (1996) and Mancktelow (1999), with properties of the Maxwell model listed in Table 2.
The strain rates (indicated as $\dot{\varepsilon}$ ) selected for studying are from $10^{-6}$ to $10^{-14} \mathrm{~s}^{-1}$, that is the same range of strain rates as used by Zhang et al. (1996, 2000) and Mancktelow (1999).

A finite-element-based commercial software (ABAQUS)

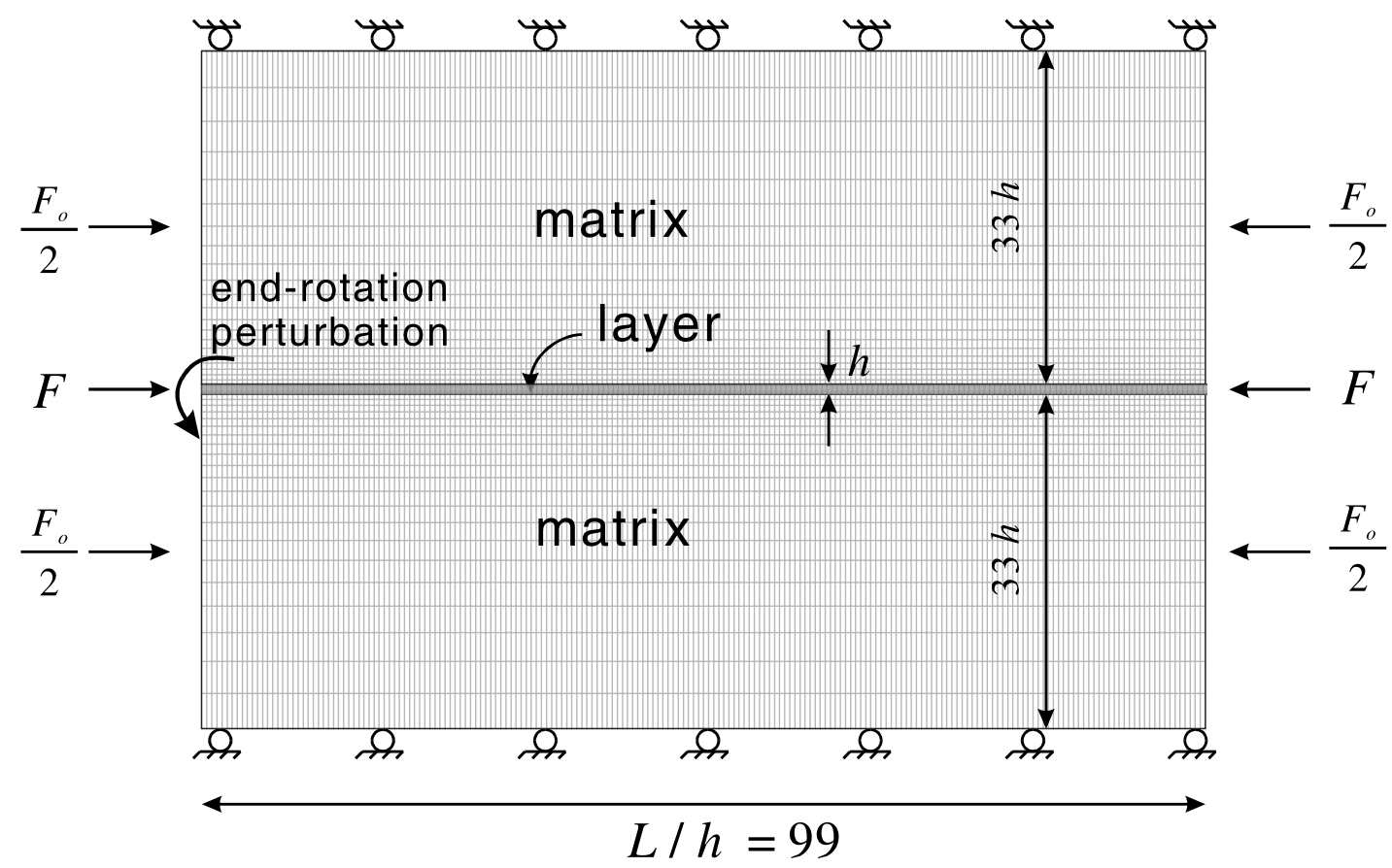

Fig. 3. Schematic setup of the analyzed model. The resultant force on the competent layer $(F)$ and on the matrix $\left(F_{\mathrm{o}}\right)$ can be computed for each node. Either a pure elastic material model or an elasto-viscous material model, for both layer and matrix, can be selected for analyzing. 
Table 2

Input material properties

\begin{tabular}{ll}
\hline$E$ & $35,000(\mathrm{MPa})$ \\
$E_{\mathrm{o}}$ & $350(\mathrm{MPa})$ \\
$\eta$ & $10^{14}(\mathrm{MPa} \mathrm{s})$ \\
$\eta_{\mathrm{o}}$ & $10^{12}(\mathrm{MPa} \mathrm{s})$ \\
$\nu$ & 0.25 \\
$\nu_{\mathrm{o}}$ & 0.25 \\
$\dot{\varepsilon}$ & $10^{-6} \sim 10^{-14}\left(\mathrm{~s}^{-1}\right)$ \\
\hline
\end{tabular}

was adopted to conduct numerical analysis of this research. This code is capable of conducting simulation based on finite strain method and the updated model configuration (Hibbit, Karlsson and Sorensen Inc., 1998). Detailed information about this software can be found in the website: www.abaqus.com. Rather than small strain theory, the use of finite strain theory is more appropriate in simulating the post-buckle behavior as the magnitude of strain may far exceed the small strain range.

\section{Influence of strain rates based on initial geometric perturbation}

For elasto-viscous material, both Zhang et al. (1996) and Mancktelow (1999) evaluated the influence of the initial perturbation. Zhang et al. (1996) concluded that a perfectly-sinusoidal small perturbation would not influence the buckling wavelength developed, which is identical to
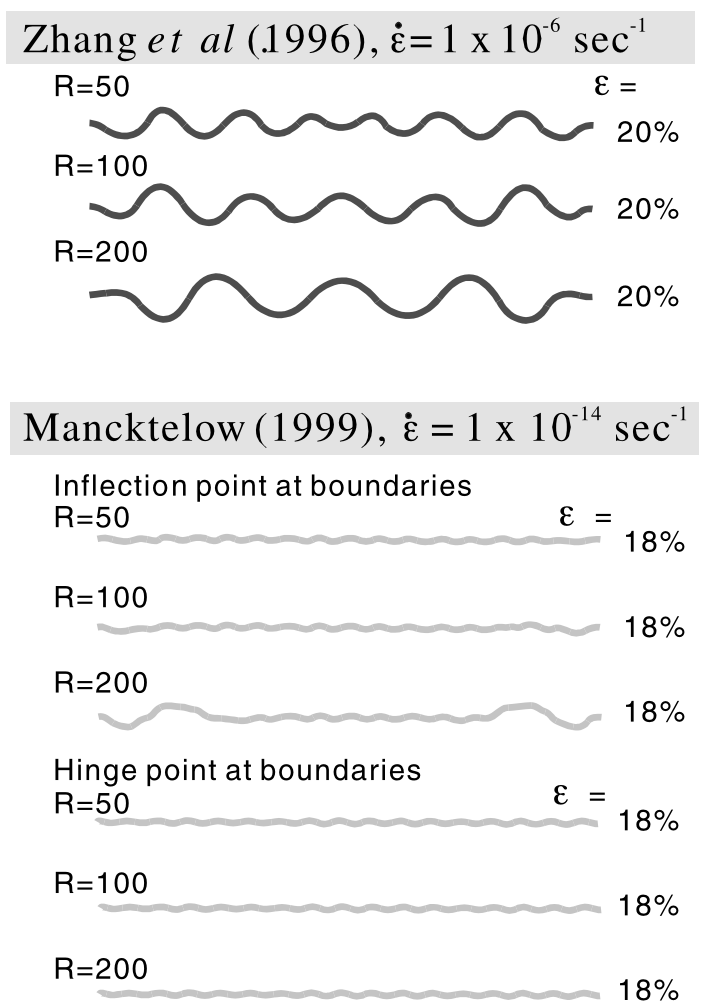

the prediction of the Biot-Ramberg dominant wavelength. In a later work, Mancktelow (1999) found that the initial geometric perturbation was amplified into folds during the compression process. It was found that the difference in applied strain rates accounts for the discrepancy in the waveform yielded (Zhang et al., 2000). This result is confirmed by our numerical analyses. Using the same numerical method (finite element method) and the same global shortening strain rate $\left(\dot{\varepsilon}=10-14 \mathrm{~s}^{-1}\right)$ as Mancktelow (1999) did, similar results were obtained as shown in Fig. 4. On the other hand, for a global shortening strain rates of $10^{-6}$ and $10^{-10} \mathrm{~s}^{-1}$, identical results to Zhang's work (shown in Fig. 4) were also obtained.

In summary, at slow strain rates, the initial geometric perturbation clearly dominates the configuration of the fold yielded by increasing its amplitude into a folding geometry. This result reflects an interesting phenomenon: other things being equal, it is the strain rate that determines whether the yielded waveform will be influenced by the initial geometric perturbation. It is therefore interesting to explore further the effects of strain rate on the folding behavior of elasto-viscous material.

\section{Influence of strain rates based on end-rotational perturbation}

\subsection{Layer compressed under constant strain rates}

The waveform developed is different for different strain
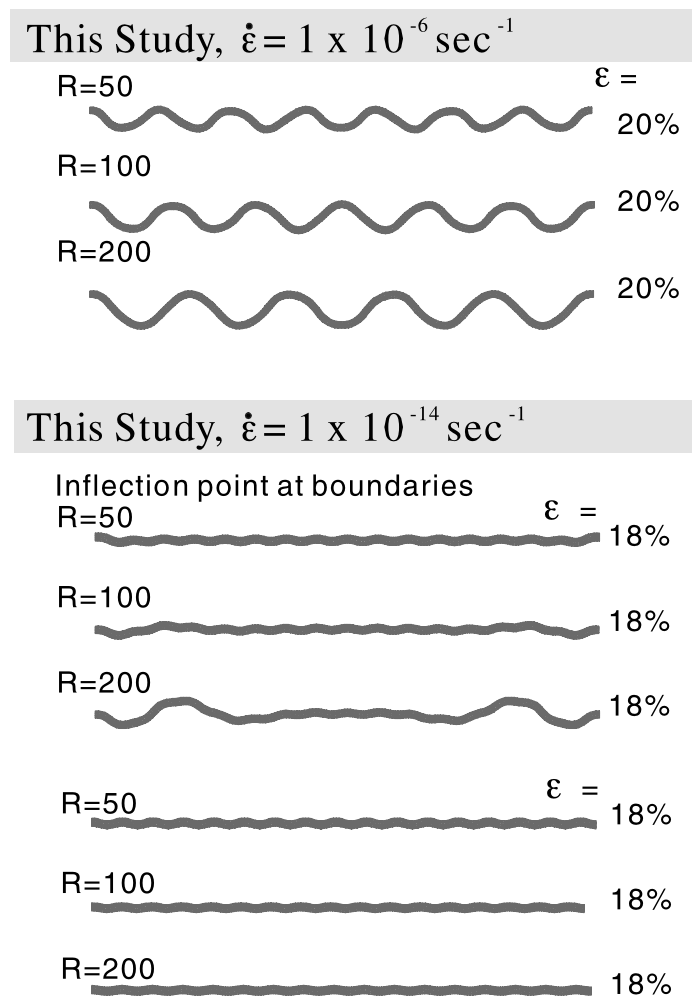

Fig. 4. Comparison of simulation results with previous works by Zhang et al. (1996) and Mancktelow (1999). 


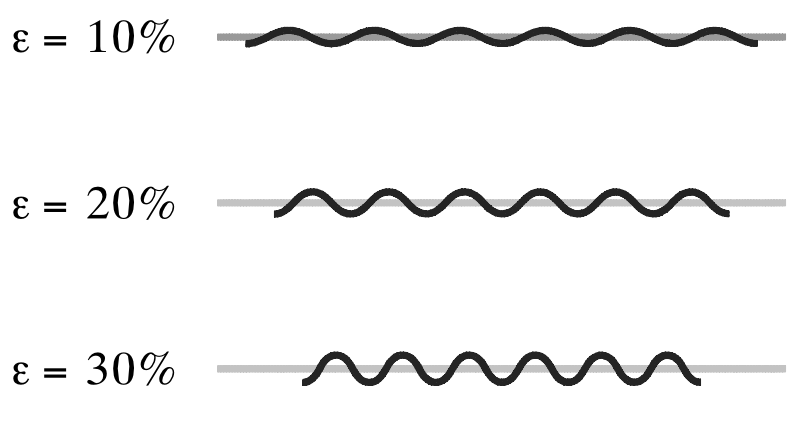

(a) elastic layer

$\varepsilon=10 \%$

$\varepsilon=20 \%$

$\varepsilon=30 \%$
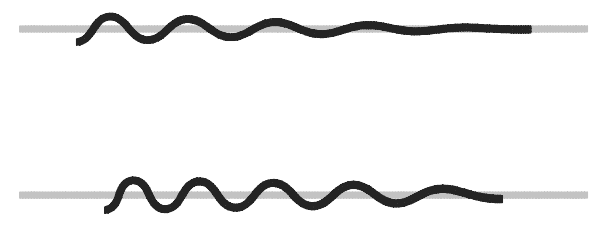

(c) elasto-viscous layer $\dot{\varepsilon}=10^{-11} \mathrm{sec}^{-1}$
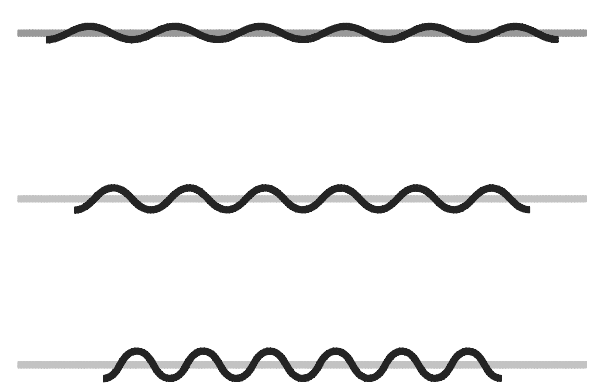

(b) elasto-viscous layer

$$
\dot{\varepsilon}=10^{-10} \sec ^{-1}
$$

Fig. 5. The waveforms developed from elastic and elasto-viscous models during various stages of lateral compression. The waveforms shown in (a) and (b) are identical. The waveforms shown in (c) and (d) are characterized by an amplitude attenuation.

rates, as illustrated in Fig. 5. The end-rotation is applied at an initial shortening distance $\left(\delta_{\mathrm{i}}\right)$ equal to $2.5 \%$ of the total length for all strain rates.

At a relatively faster strain rate $\left(\dot{\varepsilon}=10^{-10} \mathrm{~s}^{-1}\right.$ or faster; Fig. 5b), the yielded waveform is identical to that of an elastic model (Fig. 5a). Therefore, in terms of the waveform developed, the fast strain rate enables an 'elastic' response as would be expected in an elasto-viscous material.

At a relatively slow strain rate $\left(\dot{\varepsilon}=10^{-11} \mathrm{~s}^{-1}\right.$ or slower $)$, the waveform exhibits typical amplitude attenuation as depicted in Fig. 5c and d.

For the strain rates analyzed, the corresponding $\lambda_{\mathrm{d}}$ and $D_{\mathrm{e}}$ are listed in Table 3 . According to the numerical simulation, a response analogous to an elastic material has been observed for $\dot{\varepsilon}=10^{-6}$ and $10^{-10}\left(\lambda_{\mathrm{d}}=431-4.31\right)$, which is consistent with the prediction of Schmalholz and Podladchikov (2000).

On the other hand, if slower strain rates

Table 3

Relevant parameters of the analyzed cases. Remarks: $\left(l_{\mathrm{cr}}\right)_{\mathrm{v}}$ and $\left(l_{\mathrm{cr}}\right)_{\mathrm{e}}$ are the dominant wavelengths obtained from the viscous theory (Biot, 1961) and elastic theory (Currie et al., 1962), respectively. $l_{\mathrm{FEM}}$ is the wavelength obtained from numerical simulation under various strain rates. $l_{\mathrm{s}}$ is the wavelength computed from Eq. (5). $h$ is the thickness of the layer

\begin{tabular}{|c|c|c|c|c|c|c|c|c|}
\hline Type of material & $\dot{\varepsilon}(1 / \mathrm{s})$ & $\lambda_{\mathrm{d}}$ & $D_{\mathrm{e}}$ & $\left(l_{\text {cr }}\right)_{\mathrm{e}} / h$ & $\left(l_{\mathrm{cr}}\right)_{\mathrm{v}} / h$ & $l_{\mathrm{FEM}} / h$ & $F\left(10^{6} \mathrm{~N}\right)$ & $l_{\mathrm{s}} / h$ \\
\hline Elastic model & - & - & - & 16.1 & - & 16.5 & 1939 & 18.4 \\
\hline \multirow[t]{6}{*}{ Elasto-viscous model } & $1 \times 10^{-06}$ & 431.00 & $7.14 \times 10^{+3}$ & - & - & 16.5 & 1939 & 18.5 \\
\hline & $1 \times 10^{-10}$ & 4.31 & $7.14 \times 10^{-1}$ & - & - & 16.5 & 1879 & 18.6 \\
\hline & $1 \times 10^{-11}$ & 1.36 & $7.14 \times 10^{-2}$ & - & - & 19.8 & 1368 & 20.6 \\
\hline & $1 \times 10^{-12}$ & 0.43 & $7.14 \times 10^{-3}$ & - & - & 28.3 & 483 & 28.7 \\
\hline & $1 \times 10^{-13}$ & 0.14 & $7.14 \times 10^{-4}$ & - & - & 28.3 & 243 & 28.7 \\
\hline & $1 \times 10^{-14}$ & 0.04 & $7.14 \times 10^{-5}$ & - & - & 28.3 & 82 & 30.8 \\
\hline Viscous model & - & - & - & - & 16.1 & - & - & - \\
\hline
\end{tabular}




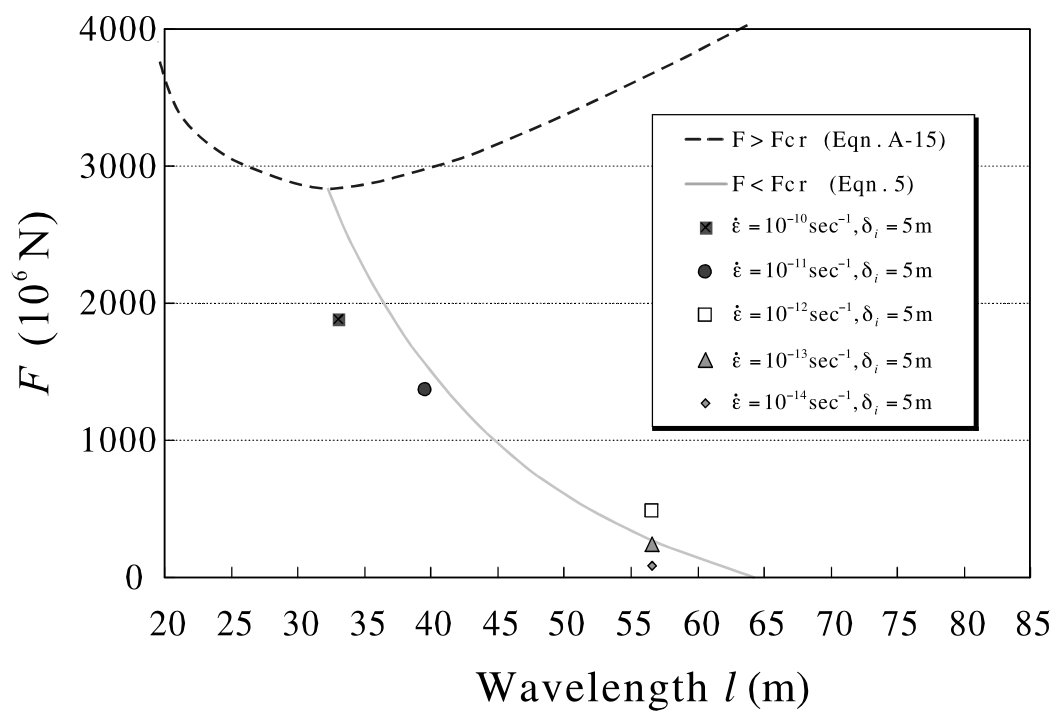

Fig. 6. The relationship between the lateral force $F$ and the resultant wavelength $l$. The dashed line and the solid line indicate the $F-l$ relationship for $F \geq F_{\text {cr }}$ and $F<F_{\text {cr }}$, respectively. The results of the numerical simulations are indicated by symbols.

$\left(\dot{\varepsilon}=10^{-13} \sim 10^{-14}\right)$ were applied $\left(\lambda_{\mathrm{d}}=0.14 \sim 0.04\right)$, the response, a waveform with attenuated amplitude, differs from the non-attenuated sinusoidal waveforms developed from the pure elastic model (Currie et al., 1962) and from the pure viscous model (Biot, 1961). Furthermore, as shown in Table 3 , the dominant wavelength, $\left(l_{\mathrm{cr}}\right)_{\mathrm{v}} / h$, for a pure viscous model is 16.1 (Eq. (1)); yet the wavelength yielded by numerical simulation, $l_{\mathrm{FEM}} / h$, under stain rates ranging from $10^{-13} \sim 10^{-14} \mathrm{~s}^{-1}$ is 28.3 . Therefore, factors other than the purely viscous behavior (Eq. (1)) may also influence the resultant waveform.

It has been found that a waveform with amplitude attenuation is possible for an elastic layer-spring model as shown in Appendix A. For the layer-spring model, the waveform with attenuated amplitude will be developed (Eqs. (A11)-(A13)), if a perturbation is applied at any $F$ less than $F_{\mathrm{cr}}$. Comparing a layer-spring with a layer-matrix model, a comparable $F-l$ relationship for $F<F_{\text {cr }}$ can be found (Jeng et al., 2001):

$F=\frac{16 \pi^{2} \bar{E} I}{l^{2}}-\frac{1}{2} \sqrt[3]{2 \bar{E} I \bar{E}_{0}^{2}}$

Comparing the $F-l$ relationship predicted by Eq. (5) with the $F-l$ relationship revealed from numerical simulation under slow strain rates, Fig. 6 shows a good resemblance of these two $F-l$ relationships. This implies that, even at slow strain rates, the elasticity may still play a role in determining the final waveform of a Maxwell material. In terms of the waveform developed, a slowly compressed elasto-viscous layer-matrix model is comparable with an elastic layer-spring model folded when $F<F_{\text {cr. }}$.

To explore what is responsible for the discrepancy in the waveforms yielded under different strain rates, the variation in energy in the folded system during the deformation process was first examined. The energy involved can be expressed as:

$E_{\mathrm{t}}=E_{\mathrm{e}}+E_{\mathrm{v}}$

where $E_{\mathrm{t}}$ is the total external energy input into the deformed system, $E_{\mathrm{v}}$ is the energy consumed due to viscous deformation, and $E_{\mathrm{e}}$ is the retained energy, which is stored in the system in the form of elastic energy.

Results of numerical simulations indicate that an increase in the total external energy is required to continuously compress the layer-matrix system (Fig. 7a and b). Comparing Fig. 7a and b, strain rate has a more significant impact on the total energy applied to the competent layer than to the matrix. The total energy provided to the competent layer significantly decreases for slower strain rates, as shown in Fig. 7b. Consequently, the elastic energy stored in the layer significantly decreases for slower strain rates, as shown in Fig. 7c. Clearly, for slower strain rates, the viscous deformation not only reduces the required energy input but also absorbs a greater portion of the input energy. In this way, the viscous behavior plays an increasingly important role in influencing the waveform developed.

The decrease in stored elastic energy at slow strain rates is reflected in the decrease in the lateral force required to maintain equilibrium of the folded system, as shown in Fig. 8, which illustrates the following phenomena:

1. For an elastic system, the lateral force $F$ remains at an almost constant magnitude in the post-buckle stage of deformation.

2. For an elasto-viscous system, $F$ drops significantly during the post-buckle phase. Comparing Fig. 5b $\left(\dot{\varepsilon}=10^{-10} \mathrm{~s}^{-1}\right)$ with Fig. 5a $\left(\dot{\varepsilon}=10^{-6} \mathrm{~s}^{-1}\right)$, the waveforms are identical, but the elastic energy stored in the system during the post-buckle stage is different because of the drop in $F$ in the slower case. 


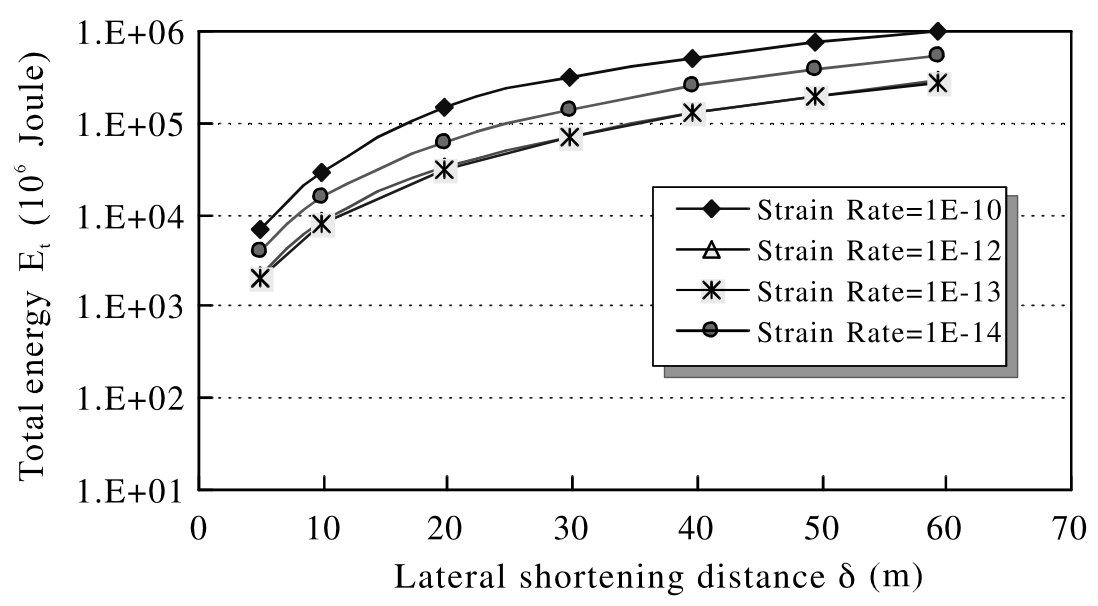

(a) Total energy applied to matrix

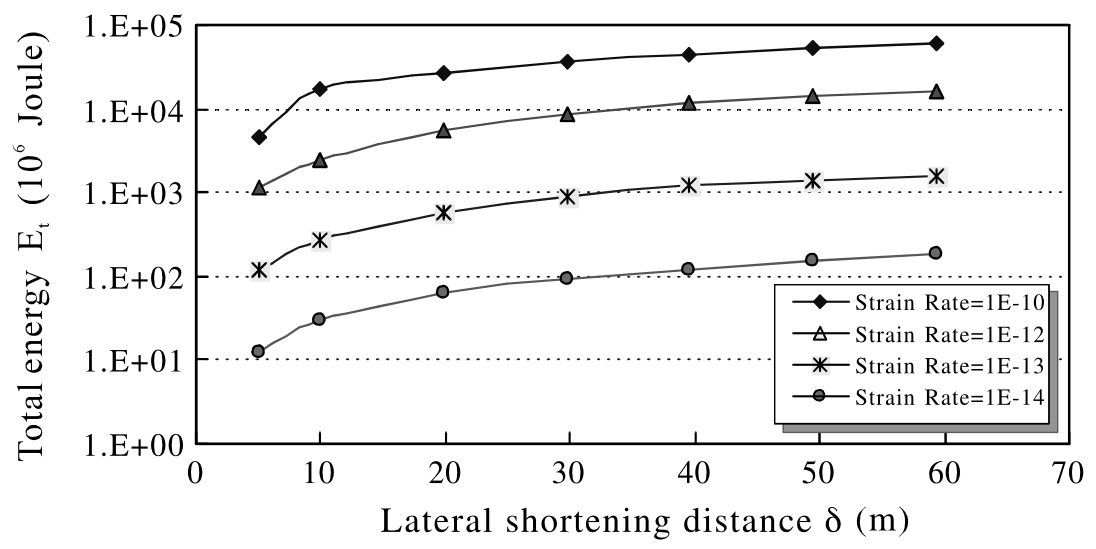

(b) Total energy applied to layer

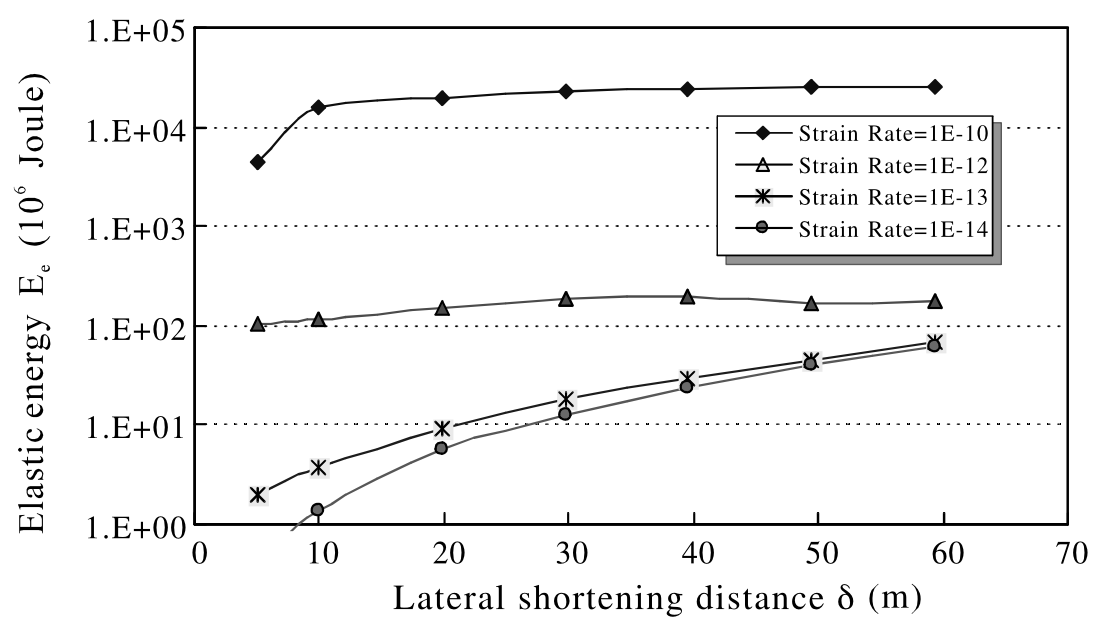

(c) Elastic energy stored in layer

Fig. 7. Variation of input energy and elastic energy during the deformation process. The total energy applied to the matrix and the layer are respectively shown in (a) and (b). The elastic energy stored in the layer during the folding process is shown in (c).

3. If the strain is very slow $\left(\dot{\varepsilon}=10^{-14} \mathrm{~s}^{-1}\right)$, the $F-\varepsilon$ curve does not exhibit a peak. The lateral force slowly increases upon further shortening of the layer.
Overall, the response of an elasto-viscous layermatrix system, for slow strain, is indeed the result of a combination of elastic and viscous behavior. Under a given strain rate, the viscous behavior determines the 


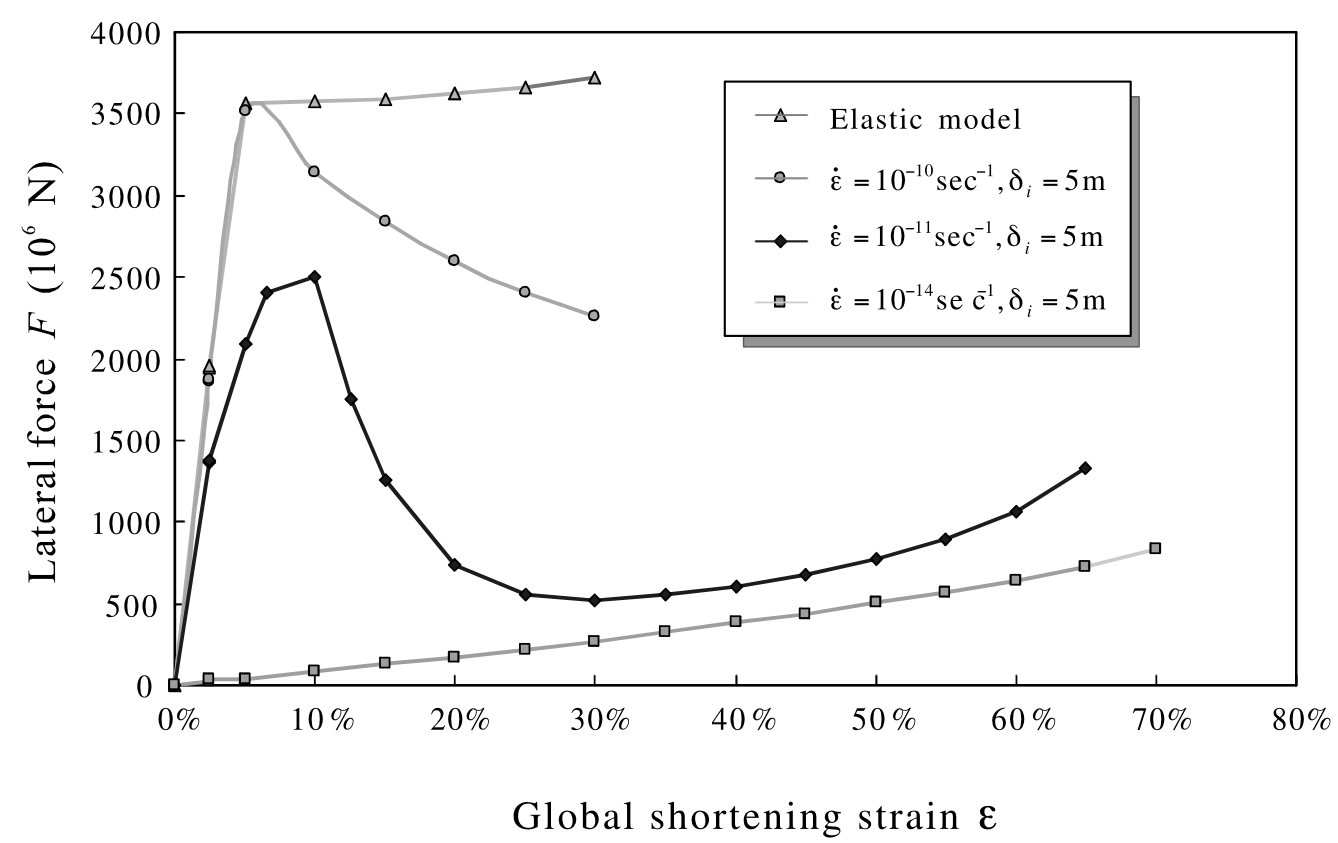

Fig. 8. Variation of lateral force during the deformation process. A slower strain rate results in less lateral force before and after buckling, compared with the results induced by a faster strain rate.

amount of elastic energy and the lateral force can be stored in the system. In this way, the remnant elastic response (energy and lateral force) can play a role, at least to some extent, in determining the final waveform (Fig. 6).

Also indicated by Fig. 6, the $F-l$ relationship observed from numerical simulations is not completely identical to the $F-l$ relationship of an elastic model (Eq. (5)). This indicates that the viscosity (e.g. the viscous competence ratio) may also play a role in determining the final wavelength. That is, in addition to the absorption of the input energy, the contribution of viscosity in determining the final waveform yet needs to be further explored.

\subsection{Layer compressed with two strain rates}

The folding behavior of an elasto-viscous layer-matrix system can be further explored by looking into the folding response under varying strain rates. As the layer is folded under an intermediate strain rate $\left(\dot{\varepsilon}=11^{-10} \mathrm{~s}^{-1}\right)$, followed by a faster or a slower post-buckle deformation $\left(\dot{\varepsilon}=10^{-10} \mathrm{~s}^{-1}\right.$ or $\left.10^{-14} \mathrm{~s}^{-1}\right)$, the variation of lateral force with lateral strain is shown in Fig. 9a and b, respectively. Fig. 9 indicates that the $F-\varepsilon$ curve, starting from a curve of constant stain rate $\left(\dot{\varepsilon}=10^{-11} \mathrm{~s}^{-1}\right)$, converges to the corresponding curves of the newly imposed constant strain rates (i.e. $\dot{\varepsilon}=10^{-10} \mathrm{~s}^{-1}$ or $\dot{\varepsilon}=10^{-14} \mathrm{~s}^{-1}$; the dashed lines shown in Fig. 9a and b).

Nevertheless, the final waveform is not only controlled by the later strain rate. If the layer is first folded at an intermediate strain rate $\left(\dot{\varepsilon}=10^{-11} \mathrm{~s}^{-1}\right)$ and then subsequently compressed under a faster one $\left(\dot{\varepsilon}=10^{-10} \mathrm{~s}^{-1}\right)$, the wave- form (shown in Fig. 10a) is first determined by the intermediate strain rate (similar waveform to the case shown in Fig. 5c). However it eventually develops a waveform with constant amplitude, comparable with the waveform yielded under fast strain rate (shown in Fig. 5b), except that the wavelength is longer. This phenomenon implies that the elastic behavior has more influence upon application of the faster subsequent strain rate. As indicated in Fig. 9, the elastic energy stored in this case $(\dot{\varepsilon}=$ $10^{-11} \rightarrow 10^{-10} \mathrm{~s}^{-1}$ ) is less than the case shown in Fig. $5 \mathrm{~b}$ $\left(\dot{\varepsilon}=10^{-10} \mathrm{~s}^{-1}\right)$, which possibly accounts for the increase in wavelength when less elastic behavior is restored.

On the other hand, if the layer is first folded at an intermediate strain rate $\left(\dot{\varepsilon}=10^{-11} \mathrm{~s}^{-1}\right)$ and then subsequently compressed under a slower one $\left(\dot{\varepsilon}=10^{-14} \mathrm{~s}^{-1}\right)$, the original waveform developed by the intermediate strain rate is amplified by later slower compression, as shown in Fig. 10b. Remarkably, the waveform developed by a constant $\dot{\varepsilon}=10^{-14} \mathrm{~s}^{-1}$ did not develop (cf. Fig. 5d). This result is consistent with the behavior observed: at a very slow strain rate, the fold is produced simply by amplifying the initial geometry perturbation. In this case, the waveform developed from the intermediate strain rate $(\dot{\varepsilon}=$ $10^{-11} \mathrm{~s}^{-1}$ ) serves as an 'initial geometric perturbation'.

\section{Discussion}

\subsection{Behavior of a one-dimensional Maxwell model subjected to compression}

The insight regarding the influence of strain rate on 


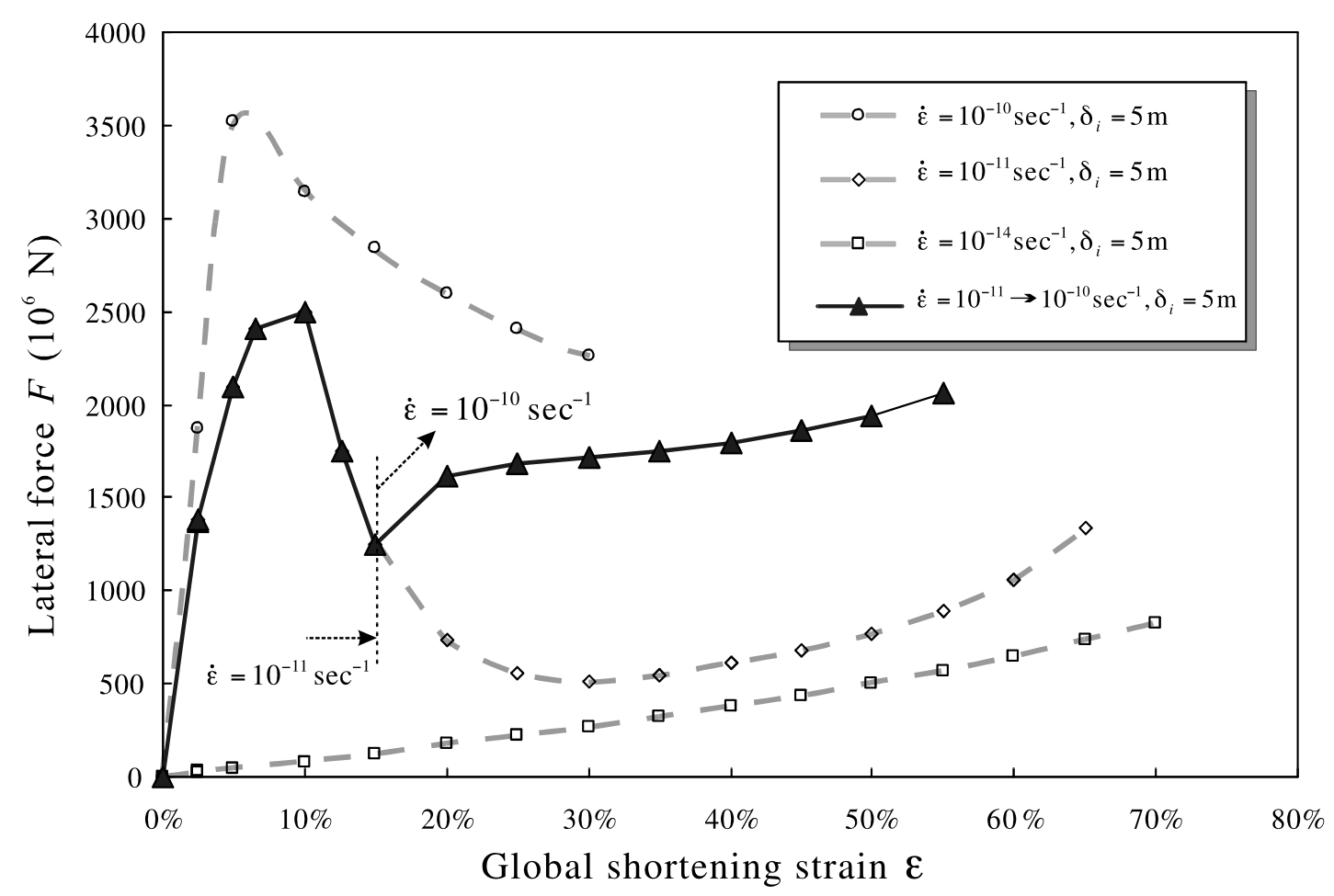

(a)

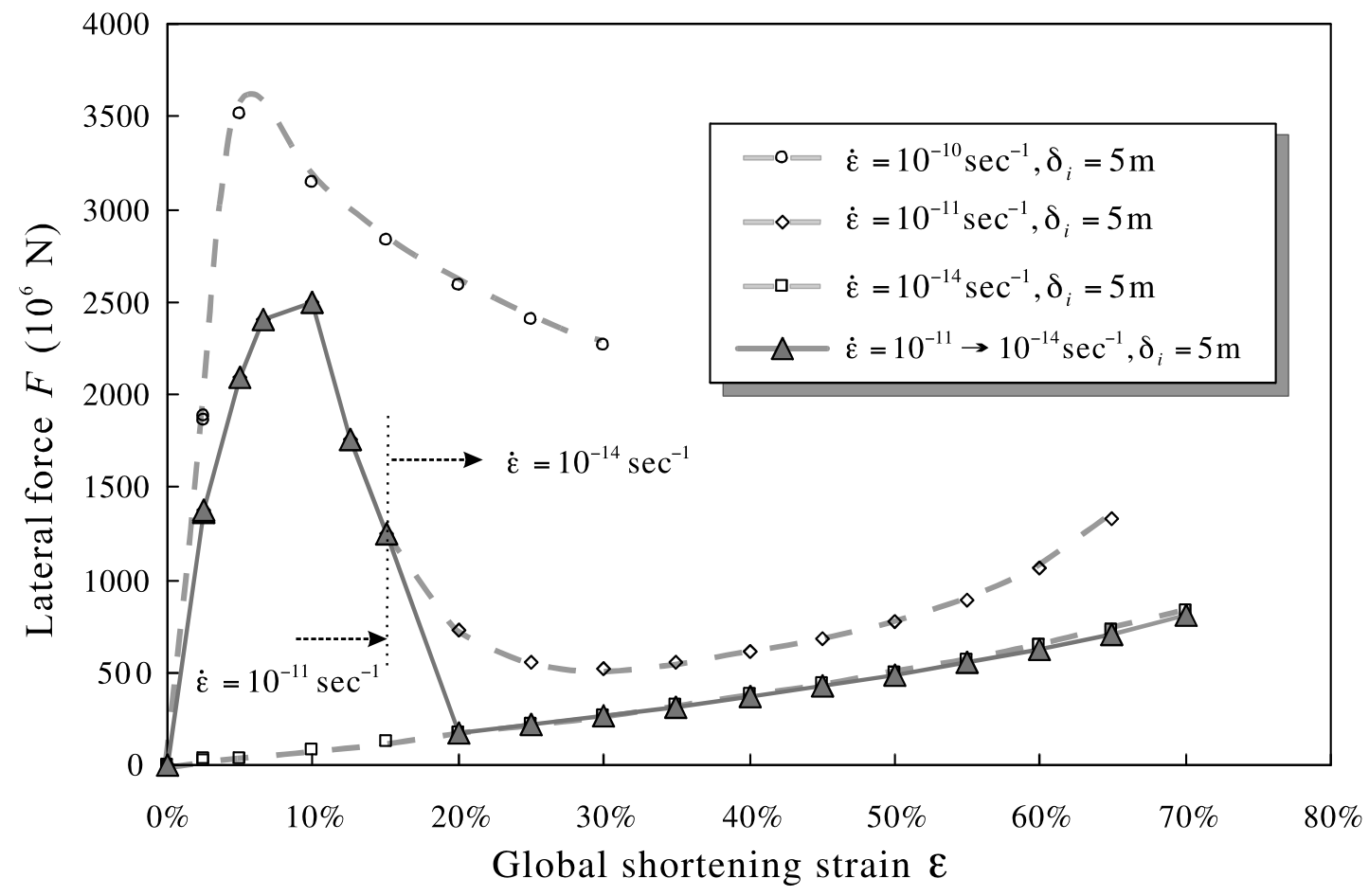

(b)

Fig. 9. Variation of lateral force $F$ during deformation process. The dashed lines indicate the $F-\varepsilon$ paths under constant strain rates. (a) The $F-\varepsilon$ curve for varying strain rates ( $\dot{\varepsilon}$ from $10^{-11}$ to $10^{-10} \mathrm{~s}^{-1}$ ) tracks though the curve with $\dot{\varepsilon}=10^{-11} \mathrm{~s}^{-1}$ at the beginning, and then converges to the curve with $\dot{\varepsilon}=10^{-10} \mathrm{~s}^{-1}$. (b) The $F-\varepsilon$ curve for varying strain rates $\left(\dot{\varepsilon}\right.$ from $10^{-11}$ to $\left.10^{-14} \mathrm{~s}^{-1}\right)$ tracks though the curve with $\dot{\varepsilon}=10^{-11} \mathrm{~s}^{-1}$ at the beginning, and then converges to the curve with $\dot{\varepsilon}=10^{-14} \mathrm{~s}^{-1}$. 
$\varepsilon=10 \%$

$\varepsilon=20 \%$
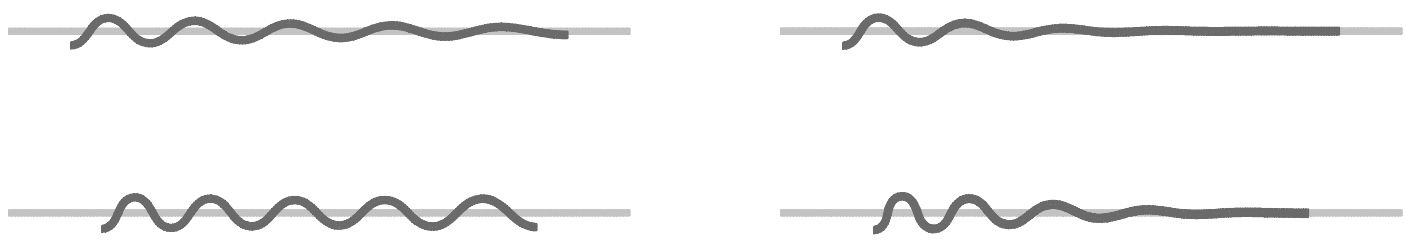

$\varepsilon=30 \%$

(a) Elasto-viscous layer

$\dot{\varepsilon}=10^{-11} \rightarrow 10^{-10} \sec ^{-1}$

(b) Elasto-viscous layer

$\dot{\varepsilon}=10^{-11} \rightarrow 10^{-14} \mathrm{sec}^{-1}$

Fig. 10. The waveform yielded under varying strain rates. The initial strain rate is changed to another strain rate when the global shortening reaches $15 \%$. (a) The waveform yielded when $\dot{\varepsilon}$ varies from $10^{-11}$ to $10^{-10} \mathrm{~s}^{-1}$, which is similar to Fig. $5 \mathrm{~b}$. (b) The waveform yielded when $\dot{\varepsilon}$ varies from $10^{-11}$ to $10^{-14} \mathrm{~s}-1$, which is similar to Fig. 5c instead of Fig. 5d.

folding behavior can be further explored by looking into the nature of Maxwell material by considering a simplified yet fundamental case, the behavior of a one-dimensional (1-D) Maxwell element as shown in Fig. 11. If this element is compressed under a constant strain rate $\dot{\varepsilon}=m\left(\mathrm{~s}^{-1}\right)$, a governing equation based on the nature of the 1-D Maxwell element can be constructed:

$\dot{\varepsilon}(t)=\frac{\dot{\sigma}(t)}{E}+\frac{\sigma(t)}{\eta}=m$

where $\sigma$ is the mean lateral stress exerted on the element ( $=F /$ cross-sectional area), $t$ is the elapsed time, $E$ is the stiffness of the spring component, $\eta$ is the viscosity of the dash-pot component and $m$ is the constant strain rate applied. Solving Eq. (7) and substituting for the initial condition ( $\varepsilon=0$ and $\sigma=0$, when $t=0)$, the lateral stress required during the lateral compression, can be expressed as:

$$
\sigma(t)=\eta m\left(1-\mathrm{e}^{-\frac{E}{\eta} t}\right)
$$

The variation of $\sigma$ with $t$ is illustrated in Fig. 11. As $t$ approaches infinity, an ultimate stress $\left(\sigma_{\infty}\right)$ exits with a magnitude of $\eta m$. That is, Eq. (8) indicates that the ultimate lateral stress $\sigma_{\infty}$ is jointly affected by the viscosity and the applied strain rate, with the transient lateral stress also affected by $E$. Therefore, this important factor $(\eta m)$ is included in the measures of the Deborah number and dominant wavelength ratio. On the other hand, the relaxation time $(\eta / E)$ determines how fast the lateral stress reaches its ultimate magnitude, which may also influence the magnitude of stored energy at an earlier stage of compression before buckling.

Since only a small amount of elastic energy can be stored

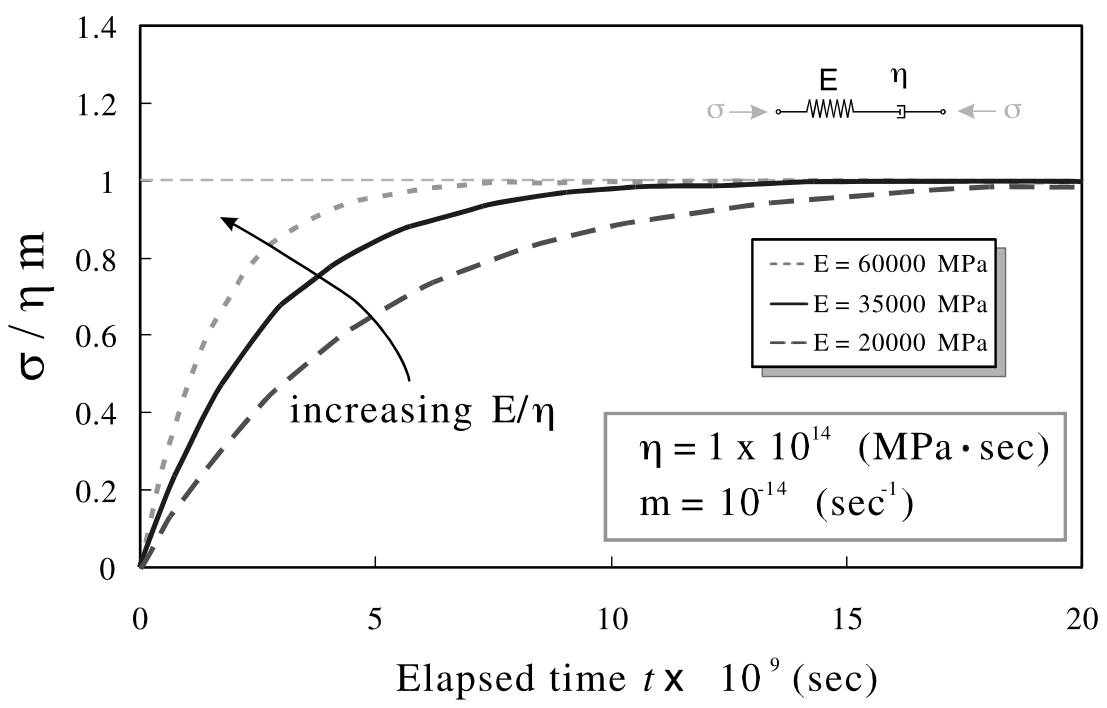

Fig. 11. The variation of lateral stress normalized by $\eta m$ with time of a 1-D Maxwell element laterally compressed at a constant strain rate $m$. This figure illustrates that a greater applied strain rate $(m)$ results in a greater lateral stress $(\sigma)$ and, meanwhile, a smaller relaxation time $(\eta / E)$ leads to faster stress transition from the initial state to the ultimate state. 


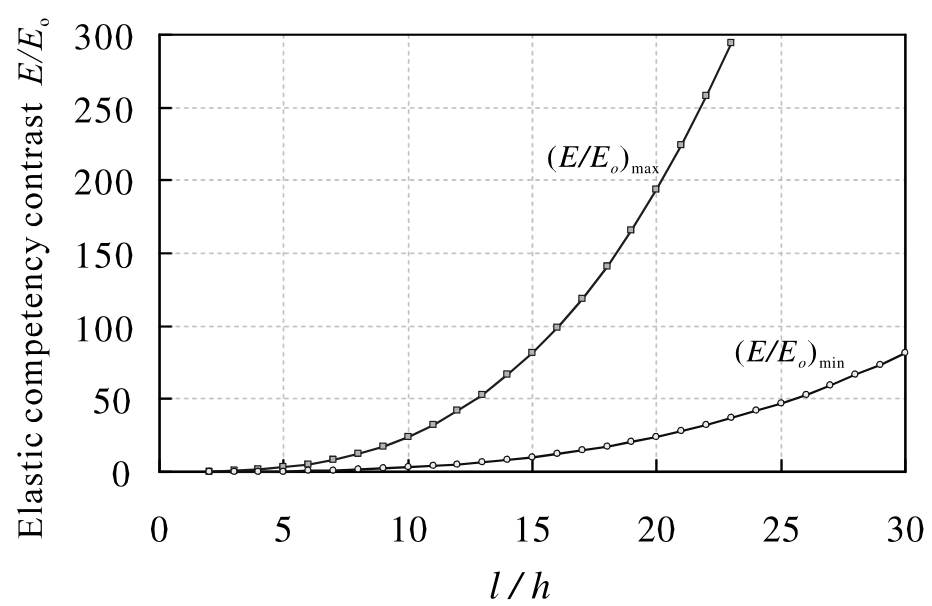

Fig. 12. The variation of elastic competence contrast with $l / h$ ratio. The upper and lower bounds are obtained from Eqs. (2) and (9), respectively.

because of viscous behavior under slow strain rates, this leads to a small lateral force such that $F$ is less than $F_{\text {cr. }}$. Consequently, a waveform with attenuated amplitude is obtained for slow strain rates based on Fig. 6, as long as the elastic behavior plays a role in determining the final waveform.

\subsection{Competence contrast of natural folds}

Observations on natural folds indicates that the arc-length to thickness ratio $\left(l_{\mathrm{a}} / h\right)$ of natural strata has a mean magnitude ranging from four to 10 (Sherwin and Chapple, 1968; Shimamoto and Hara, 1976). The maximum range of $l_{\mathrm{a}} / h$ ratio observed varies from two to 30 . It has been discussed that a direct estimation of the viscous competence contrast $\left(\eta / \eta_{\mathrm{o}}\right)$, based on the observed $l_{\mathrm{a}} / h$ ratio and Eq. (1), may lead to an underestimation of the actual competence contrast. In particular, the contribution of elastic competence contrast should be also considered (Price and Cosgrove, 1990; Schmalholz and Podladchikov, 2000).

Numerical analyses of elasto-viscous models indicate that, for a particular $E / E_{0}$, the $l / h$ ratio may increase with slower applied strain rates. The $l / h$ ratio developed can be greater than $\left(l_{\text {cr }}\right)_{\mathrm{e}} / h$ ratio of pure elastic material (Eq. (2)) but is not greater than a maximum magnitude of $l_{3} / h$. This maximum wavelength $l_{3}$ is defined in Fig. A3 and can be expressed as (based on Eq. (5)):

$l_{3}=4 \pi h \sqrt[3]{\frac{E}{E_{\mathrm{o}}}}=2\left(l_{\mathrm{cr}}\right)_{\mathrm{e}}$

Therefore, the upper and lower bounds of elastic competence contrast of natural folded stratum can be estimated based on Eqs. (2) and (9) as:

$$
\begin{aligned}
& \left(\frac{E}{E_{\mathrm{o}}}\right)_{\max }=\left(\frac{1}{4 \pi} \frac{l_{3}}{h}\right)^{3}=\left(\frac{1}{4 \pi} \frac{2 l_{\mathrm{e}}}{h}\right)^{3} \\
& \left(\frac{E}{E_{\mathrm{o}}}\right)_{\min }=\left(\frac{1}{4 \pi} \frac{l_{\mathrm{e}}}{h}\right)^{3}
\end{aligned}
$$

Fig. 12 shows the variation of $\left(E / E_{0}\right)_{\max }$ and $\left(E / E_{0}\right)_{\min }$ with $l / h$ ratio. It follows that the slower the strain rate during the folding process, the lower the elastic competence contrast a particular $l / h$ ratio represents.

\section{Conclusion}

The influence of strain rate on the waveform of folding is explored in this paper through the adoption of an endrotational method, which allows the effect of the initial geometric perturbation to be excluded. The post-buckle behavior of the folded system, including the variation of energy and lateral force, is also examined, especially the differing responses for varying strain rates.

It is found that the response is analogous to that of elastic material for fast strain rates, which is consistent with the conclusion of previous studies. However, if the strain rate is relatively slow, the folding behavior is in fact a result of both viscous and elastic behavior. For slow strain rates, the viscosity plays an important role in reducing the input energy and the elastic energy stored in the layer. Furthermore, the influence of elasticity can still be observed for slow strain rates.

If the compression process occurs under two different strain rates, the waveform depends both on the initial strain rate inducing buckling and on the final strain rate applied during the post-buckle phase of deformation. If the final strain is relatively fast, the final waveform will be similar to the one developed by a constant fast strain rate, since a substantial amount of elastic energy can be accumulated during the subsequent faster deformation (Fig. 9a). The initial waveform (e.g. attenuated amplitude) will disappear as the later elastic behavior dominates the final waveform.

On the other hand, if the final strain rate is relatively slow, the initial waveform will be retained and further amplified during the slower post-buckle deformation. This results from the phenomenon that an initial geometric perturbation will be amplified into a fold if the strain rate is very slow. 
The mean crustal strain rate induced by the convergence of plates is found to be within the order of $10^{-14}$ per second (Price, 1975; Yu et al., 1997). Therefore, viscous folding behavior is favored in this situation. However, it cannot be precluded that, in certain local areas where stress (or strain) concentration exists, the strain rate can be a few orders of magnitude greater than this global crustal strain rate and, thus, more influence of elasticity can be involved in the folding behavior.

\section{Acknowledgements}

This paper benefited from the thorough reviews by Neil S. Mancktelow, whose comments greatly enhance the technical soundness of this paper. The supports from the National Science Council of Taiwan, NSC89-2211-E002-150 and NSC89-2211-E002-152, are acknowledged.

\section{Appendix A. Theoretical basis}

\section{A.1. Layer-spring model}

First, considering a layer supported by elastic springs, the governing equation for buckle folding is (Karman and Biot, 1940):

$Y^{\prime \prime \prime \prime}(x)+\frac{F}{E I} Y^{\prime \prime}(x)+\frac{K}{E I} Y(x)=0$

where $Y, E$ and $I$ are the vertical displacement, Young's modulus and the moment of inertia of the layer, respectively, $K$ is the stiffness of the spring and $F$ is the horizontal force required to buckle the competent layer.

If the layer is surrounded by springs on both sides as shown in Fig. A1a, the contribution of the spring should be doubled and the governing equation has the following form:

$Y^{\prime \prime \prime \prime}(x)+\frac{F}{E I} Y^{\prime \prime}(x)+\frac{2 K}{E I} Y(x)=0$

Solving Eq. (A2), the characteristic value $\lambda$ can be determined in terms of $F, E, I$ and $K$ as:

$\lambda= \pm \sqrt{\frac{-F \pm \sqrt{F^{2}-8 E I K}}{2 E I}}$

Based on Eq. (A3), the solution of Eq. (A2) depends on the relative magnitude of the exerted force $F$ and the rigidity of the layer and the springs $(\sqrt{8 E I K})$. Accordingly, a critical force $F_{\text {cr }}$ is defined as:

$F_{\text {cr }}=\sqrt{8 E I K}$

For $F>F_{\text {cr }}$, the solution of Eq. (A2) is a wave comprised of two frequencies:

$Y(x)=a_{1} \sin m_{1} x+b_{1} \cos m_{1} x+c_{1} \sin n_{1} x+d_{1} \cos n_{1} x$

where $a_{1}, b_{1}, c_{1}, d_{1}$ are constants determined by boundary conditions, and $m_{1}$ and $n_{1}$ represent the mechanical characteristics of the system, which can be expressed in terms of $F$, $E, I$ and $K$ as:

$m_{1}=\sqrt{\frac{F+\sqrt{F^{2}-8 E I K}}{2 E I}}$

$n_{1}=\sqrt{\frac{F-\sqrt{F^{2}-8 E I K}}{2 E I}}$

The wavelengths corresponding to $m_{1}$ and $n_{1}$ are:

$l_{1}=\frac{2 \pi}{n_{1}}$
$l_{2}=\frac{2 \pi}{m_{1}}$

The waveform described by Eq. (A5) is comprised of two frequencies with non-attenuated amplitudes. This waveform, referred to as the Type A waveform, is shown in Fig. A2a.

When $F=F_{\text {cr }}$, the waveform merges from two frequencies to a single frequency as:

$Y(x)=a_{2} \sin n_{2} x+b_{2} \cos n_{2} x$

where $a_{2}$ and $b_{2}$ are constants determined by boundary condition, and $n_{2}$ can be expressed as:

$n_{2}=\sqrt{\frac{F}{2 E I}}=\sqrt[4]{\frac{2 K}{E I}}$

This waveform, referred to as the Type B waveform, is a sinusoidal wave comprised of only one frequency with a non-attenuated amplitude as illustrated in Fig. A2b.

When $F \geq F_{\text {cr }}$, the relationship between the applied force $F$ and the resultant wavelength $(l)$ can be obtained as (Karman and Biot, 1940):

$F=\frac{4 \pi^{2}}{l^{2}} E I+\frac{2 K l^{2}}{4 \pi^{2}}$

According to Eq. (A9), an exerted force $F$ leads to buckle folding with a wavelength $l$ as long as $F \geq F_{\text {cr. When }}$ $F=F_{\text {cr }}$, a corresponding wavelength $l_{\text {cr }}$ is found to be:

$l_{\text {cr }}=2 \pi \sqrt[4]{\frac{E I}{2 K}}$

Yet, when $F<F_{\text {cr }}$, folding of the layer is still possible. This needs to be discussed in detail. When $F<F_{\text {cr }}$, based on Eq. (A3), the solution of Eq. (A2) has the following form:

$Y(x)=\mathrm{e}^{-m_{3} x}\left(a_{3} \cos n_{3} x+b_{3} \sin n_{3} x\right)$

where $a_{3}$ and $b_{3}$ are constants determined by boundary condition, $m_{3}$ and $n_{3}$ are characteristic values determined by the exerted force $F$ and the property of materials $(E, I$ and $K)$ as:

$m_{3}=\sqrt{\frac{-F+\sqrt{8 E I K}}{4 E I}}$ 
spring

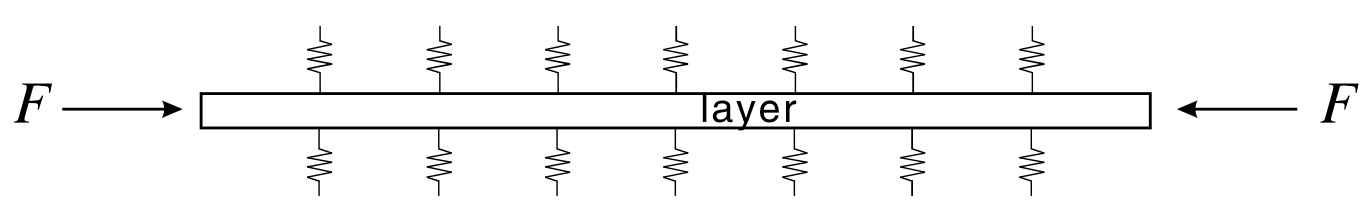

(a) layer embedded in spring

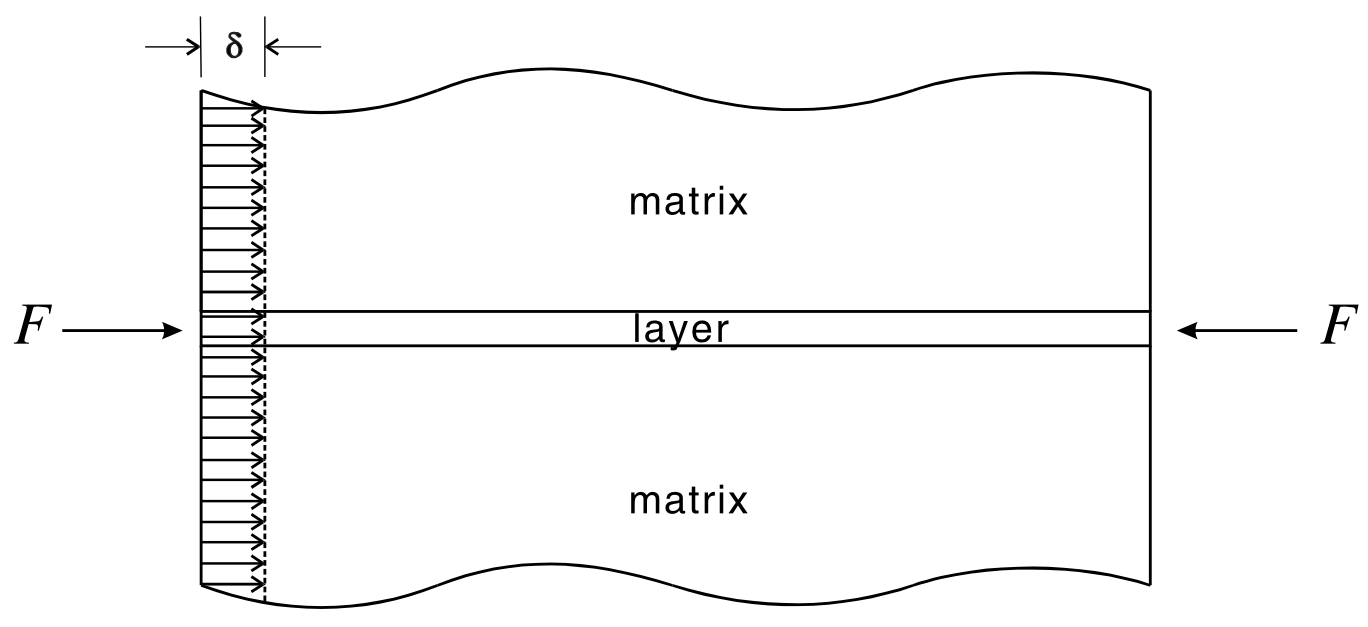

(b) layer embedded in matrix

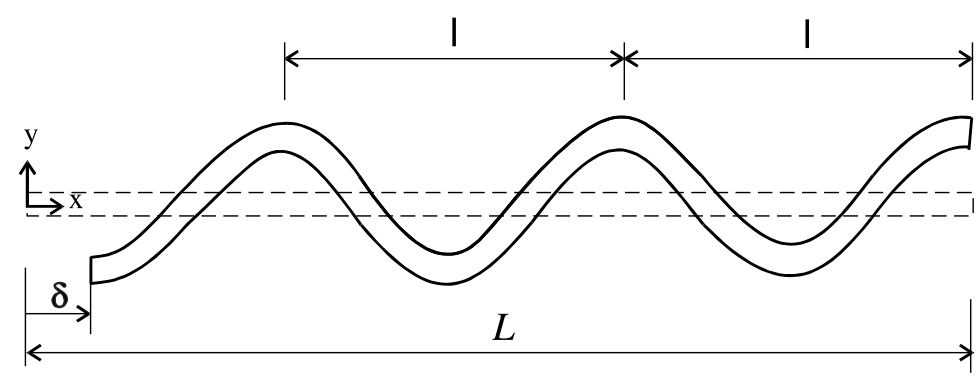

(C) Coordinate and corresponding definition for a buckled layer

Fig. A1. Schematic illustrations for the analyzed models. (a) Layer-spring model. (b) Layer-matrix model. (c) Illustration for the corresponding definitions.

$n_{3}=\sqrt{\frac{F+\sqrt{8 E I K}}{4 E I}}$

Based on Eq. (A11), the fold has only one frequency and the amplitude tends to decay as $x$ (the distance from the perturbed end as indicated in Fig. A1c) increases. This type of waveform is referred to as the Type $\mathrm{C}$ waveform, which basically is still a sinusoidal wave, however, with amplitude attenuation feature as depicted in Fig. A2c. The amplitude attenuates as the distance from the perturbed end increases.

When $F<F_{\text {cr }}$, the relation of $F$ with the yielded wave- length $l$ can be expressed as:

$F=\frac{16 \pi^{2} E I}{l^{2}}-\sqrt{8 E I K}$

Fig. A2 illustrates the $F-l$ relationships when $F<F_{\text {cr }}$ (Eq. (A13)) and $F \geq F_{\text {cr }}$ (Eq. (A9)). Eq. (A13) indicates that: (1) folding is possible even when $F$ is less than $F_{\text {cr }}$; (2) the smaller the $F$, the longer the wavelength $l$ and the greater the amplitude attenuation; and (3) when $F<F_{\text {cr }}$, the wavelength has an upper limit $l_{3}$ (illustrated in Fig. A2), which can be expressed as:

$l_{3}=\frac{4 \pi \sqrt{E I}}{\sqrt[4]{8 E I K}}$ 


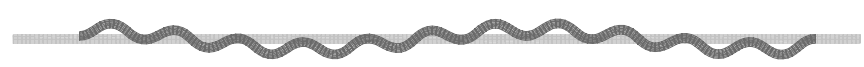

(a) Type $A$ waveform $\left(F>F_{c r}\right)$

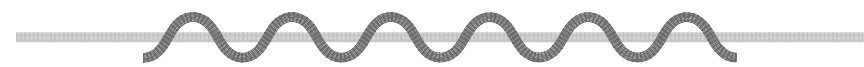

(b) Type $B$ waveform $\left(F=F_{c r}\right)$

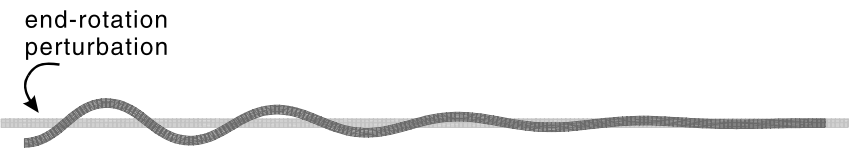

(c) Type $C$ waveform $\left(F<F_{c r}\right)$

Fig. A2. Schematic illustration of the three types of waveforms obtained from numerical analyses. (a) Type A waveform comprises of two frequencies, which can be yielded when $F>F_{\text {cr. }}$. (b) Type B waveform is a single-frequency-wave with a constant amplitude over the full length of the competent layer (when $F=F_{\text {cr }}$ ). (c) Type $\mathrm{C}$ waveform is a single-frequecy-wave characterized with an amplitude attenuation away from the perturbed end (when $F<F_{\text {cr }}$ ).

\section{A.2. Layer-matrix model}

As the plate-shaped layer is surrounded by matrix instead of springs (Fig. A1b), an $F-l$ relationship similar to Eq. (A8) can be obtained (Currie et al., 1962):

$F=\frac{4 \pi^{2}}{l^{2}} \bar{E} I+\frac{\bar{E}_{\mathrm{o}} I}{2 \pi}$

where $\bar{E}=E /\left(1-\nu^{2}\right) ; \bar{E}_{\mathrm{o}}=E_{\mathrm{o}} /\left(1-\nu_{\mathrm{o}}^{2}\right) ; E_{\mathrm{o}}$ is the Young's modulus of the matrix, and $\nu$ and $\nu_{\mathrm{o}}$ are the Poisson ratio of the competent layer and matrix, respectively.

Eq. (A15) describes a $F-l$ curve, which has a similar geometry to that of the layer-spring system as shown in Fig. A2 (upper part of the curve). Therefore, a critical force $F_{\text {cr }}$ and the corresponding wavelength $l_{\text {cr }}$ can be

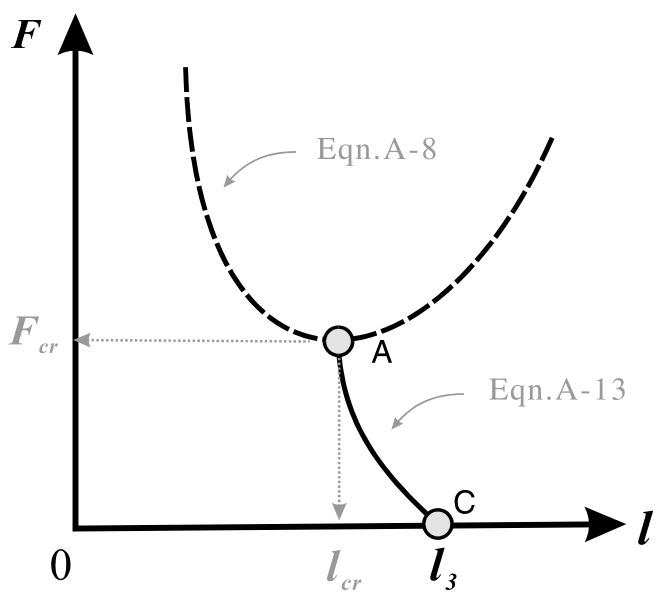

Fig. A3. The $F-l$ relationship for a layer embedded in spring (modified after Karman and Biot, 1940). For $F>F_{\text {cr }}$, the developed waveform is comprised of two frequencies (or wavelengths). For $F=F_{\text {cr }}$, the waveform has a single frequency and constant amplitude. For $F<F_{\text {cr }}$, the waveform also has a single frequency yet with attenuated amplitude. accordingly determined as:

$F_{\text {cr }}=\frac{3}{2} \bar{E}_{\mathrm{o}} \sqrt[3]{2 \frac{\bar{E}}{\bar{E}_{\mathrm{o}}}} I=\frac{3}{2} h \bar{E}_{\mathrm{o}} \sqrt[3]{\frac{\bar{E}}{6 \bar{E}_{\mathrm{o}}}}$

$l_{\mathrm{cr}}=2 \pi h \sqrt[3]{\frac{\bar{E}}{6 \bar{E}_{\mathrm{o}}}}$

where $h$ is the thickness of the layer.

\section{References}

Abbassi, M.R., Mancktelow, N.S., 1990. The effect of initial perturbation shape and symmetry on fold development. Journal of Structural Geology 12, 273-282.

Abbassi, M.R., Mancktelow, N.S., 1992. Single layer buckle in non-linear material-I. Experimental study of fold development from an isolated initial perturbation. Journal of Structural Geology 14, 85-104.

Biot, M.A., 1959. Folding of a layered viscoelastic medium derived from an exact stability theory of a continuum under initial stress. Quarterly of Applied Mathematics 17, 185-204.

Biot, M.A., 1961. Theory of folding of stratified viscoelastic media and its implications in tectonics and orogenesis. Geological Society of America Bulletin 72, 1595-1620.

Blay, P.K., Cosgrove, J.W., Summers, J.M., 1977. An experimental investigation of the development of structures in multilayers under the influence of gravity. Journal of the Geological Society of London 133, 329-342.

Cobbold, P.R., 1976. Fold shapes as functions of progressive strain. Philosophical Transactions of the Royal Society of London A 283, $129-138$.

Cobbold, P.R., 1977. Finite-element analysis of fold propagation - a problematic application? Tectonophysics 38, 339-353.

Currie, J.B., Patnode, H.W., Trump, R.P., 1962. Development of folds in sedimentary strata. Geological Society of America Bulletin 73, 655-674.

Dieterich, J.H., Carter, N.L., 1969. Stress-history of folding. American Journal of Science 267, 129-154.

Fletcher, R.C., 1974. Wavelength selection in the folding of a single layer 
with power-law rheology. American Journal of Science 274, 10291043.

Fletcher, R.C., 1977. Folding of a single viscous layer: exact infinitesimalamplitude solution. Tectonophysics 39, 593-606.

Hibbit, Karlsson and Sorensen, Inc. 1998. ABAQUS Theory Manual, Hibbit, Karlsson and Sorensen Inc., Rhode Island.

Hudleston, P.J., Stephansson, O., 1973. Layer shortening and folding shape development in the buckling of single layers. Tectonophysics 17, 299-321.

Hunt, G.W., Mühlhaus, H.B., Whiting, A.I.M., 1996. Evolution of localized folding for a thin elastic layer in a softening visco-elastic medium. Pure and Applied Geophysics 146, 229-252.

Jeng, F.S., Lu, C.Y., Chang, N.G., 2001. Buckle folding of elastic strata. Proceedings of 10th International Conference on Computer Methods and Advances in Geomechanics, Tucson, USA, pp. 1309-1312.

Johnson, A.M., 1970. Physical Processes in Geology. Freeman, Cooper, San Francisco.

Johnson, A.M., 1977. Styles of Folding. Elsevier, New York.

Johnson, A.M., Fletcher, R.C., 1994. Folding of Viscous Layers. Columbia University Press, New York.

Karman, T.V., Biot, M.A., 1940. Mathematical Methods in Engineering. McGraw-Hill, New York.

Mancktelow, N.S., 1999. Finite-element modelling of single-layer folding in elasto-viscous materials: the effect of initial perturbation geometry. Journal of Structural Geology 21, 161-177.

Mancktelow, N.S., Abbassi, M.R., 1992. Single layer buckle folding in non-linear materials - II. Comparison between theory and experiment. Journal of Structural Geology 14, 105-120.

Price, N.J., 1975. Rates of deformation. Journal of the Geological Society of London 131, 553-575.

Price, N.J., Cosgrove, J.W., 1990. Analysis of Geological Structures. Cambridge University Press, Cambridge.

Ramberg, H., 1963. Fluid dynamics of viscous buckling applicable to fold- ing of layered rocks. Bulletin of American Association of Petroleum Geologists 47, 484-505.

Ramberg, H., 1964. Selective buckling of composite layers with contrasted rheological properties, a theory for simultaneous formation of several orders of folds. Tectonophysics 1, 307-341.

Schmalholz, S.M., Podladchikov, Y.Y., 1999. Buckling versus folding: importance of viscoelasticity. Geophysical Research Letters 26, 2641-2644.

Schmalholz, S.M., Podladchikov, Y.Y., 2000. Finite amplitude folding: transition from exponential to layer length controlled growth. Earth and Planetary Science Letters 179, 363-377.

Sherwin, J.A., Chapple, W.M., 1968. Wavelengths of single layer folds: a comparison between theory and observation. American Journal of Science 266, 167-179.

Shimamoto, T., Hara, I., 1976. Geometry and strain distribution of singlelayer folds. Tectonophysics 30, 1-34.

Weiss, L.E., 1972. The Minor Structures of Deformed Rocks. Springer, Berlin.

Whiting, A.I.M., Hunt, G.W., 1997. Evolution of nonperiodic forms in geological folds. Mathematical Geology 29, 705-723.

Williams, J.R., Lewis, R.W., Zienkiewicz, O.C., 1977. A finite-element analysis of the role of initial pertabations in the folding of a single viscous layer. Tectonophysics 45, 187-200.

Yu, S.-B., Chen, H.-Y., Kuo, L.-C., 1997. Velocity field of GPS stations in the Taiwan area. Tectonophysics 274, 41-59.

Zhang, Y., Hobbs, B.E., Ord, A., Mühlhaus, H.B., 1996. Computer simulation of single-layer buckling. Journal of Structural Geology 18, 643-655.

Zhang, Y., Mancktelow, N.S., Hobbs, B.E., Ord, A., Mühlhaus, H.B., 2000. Numerical modelling of single-layer folding: clarification of an issue regarding the possible effect of computer codes and the influence of initial irregularities. Journal of Structural Geology 22, 1511-1522. 